\title{
Toward a More Credible Principle of Beneficence
}

\section{Prasasti Pandit ${ }^{1}$ (i)}

Received: 30 April 2020 / Revised: 28 July 2021 / Accepted: 6 September 2021 /

Published online: 10 September 2021

(C) Indian Council of Philosophical Research 2021

\begin{abstract}
My objective of this paper is to suggest and workout a more credible form of the Principle of Beneficence from the common essential elements of the three major ethical theories (Deontology, Utilitarianism and Virtue Ethics) that will try to overcome the over-demanding objection of Utilitarianism and the rigorism of Kant's Deontology. After analyzing these three moral systems, I find that beneficence lies within the very essence of humanity. Human beings are superior to other creatures in the world due to rationality and humanity. From the humanitarian ground, a common goodness lies within every human. Beneficence, as a moral principle, is derived from this inner humanity of every individual. Despite their initial differences, utilitarianism, deontology and virtue ethics recognize this fundamental humanitarian disposition of doing good for all as a part of being a morally better person. The principle of beneficence as I suggest, is different from its consequential utilitarian notion suggested by Mill. This version of beneficence is more credible as it does not impose excessive demands upon an individual to develop any maximum beneficial outcome following utilitarian calculation of beneficence over cost, and it also strives to overcome the rigorous duty-based theory of Kantian deontology by appealing to the fundamental virtue of humanity. Finally, the credibility of this form of beneficence comes from the underlying transcendental humanism which is the chief feature of Indian tradition.
\end{abstract}

Keywords Beneficence $\cdot$ Benevolence $\cdot$ Commonness · Utilitarianism · Deontology · Virtue ethics $\cdot$ Justice $\cdot$ Virtue of humanity $\cdot$ Inner goodness

Prasasti Pandit

prasasti1moon@gmail.com

1 Department of Philosophy, West Bengal Education Service, Kolkata, West Bengal, India 


\section{Introduction}

Moral philosophy is an inquiry of the rules, principles and virtues that guide every human action and behavior. Among them, the Principle of Beneficence is an established one. The word Beneficence is derived from its Latin origin 'bene' which means well or good and 'facere' means to make; while benevolence is coined from 'bene' and 'volens' which implies a will or disposition. In the field of morality, beneficence carries normative importance which refers to do an action to benefit others, whereas, benevolence is regarded as a virtue or good character trait of being disposed to act to benefit others.

\section{Beneficence: The Fundamental Principle of Morality}

Being a social person, a human being cannot always be considered as being confined within one's own self, since an individual is situated within a complex web of social relationships (MacIver \& Page, 1949). Society and individuals are interlinked with one another, and being a social person, one has to interact with other people. Ethics guides us the morally right way of these social interactions. A person can be regarded as social and morally better human when he not only interacts with other people in right manner, but when he is disposed to do good for others beyond his own self. Hence, ethics is necessarily other-regarding. Beneficence as a moral principle refers the normative significance of doing good for all. The study of ethics transcends individuals from their own selves toward others, and toward for the good of all. In this paper, I will argue that the principle of beneficence is the fundamental principle of ethics since it is intrinsically connected with the very essence of morality.

\section{Beneficence is The Concept of Well-being for all: Individual and Community}

The moral worth of beneficence provides us the concept of morally good life. However, we cannot avoid individual good since individual good is always related with the community good. From the history of moral philosophy, we can find the views of Aristotle (1925), and the views of eighteenth century philosophers such as Cumberland (1672), Butler (1869) and Hutcheson (1725) who redefine the concept of self-love or self-beneficence as the moral perfection of a being that unites self-beneficence with the beneficence toward other-beings and thus bridges the gap between these two.

Aristotle explains his notion of beneficence from self-love. For him, self-love does not necessarily imply self-centeredness. A person who is guided by the rational part of his soul, despite his concern about his own self, acts justly. Aristotle regards that person as the true lover of self. According to Aristotle, such a 
lover of self is always guided by reason and always disposed to virtuous deeds. By doing noble acts, the person improves himself toward a morally better person.

According to Cumberland, while promoting the common good individuals will inevitably increase their own good. For him, the individual possesses a selfless natural inclination to pursue the common good, and this inclination to do the common good for all is a virtue named benevolence.

Butler finds human nature is naturally disposed to benevolence for his fellowbeings, and there is no such confrontation between self-love and community love as he views human being as a whole with equal importance and proper balance of selflove and social-love. For him, self-love which is guided with reason and conscience leads to the pursuit of general happiness with the proper accordance of conscience and reasonable benevolence and reasonable self-love.

Hutcheson also believes that human nature is naturally disposed to benevolence for fellow-beings. For him, self-love is undeniable for the motivation of actions, but it should produce moral goodness. He explains this view with his notion of moral sense which is capable of approving or disapproving moral virtues and vices.

On the contrary, Hobbes (1651) promoted psychological egoism by claiming that the absolute basic principle for human nature is nothing but self-interest. All humans always act from self-interest. The ultimate goal of every human action is to promote self-pleasure. Following this theory, any action which promotes the common good is deep down motivated from egoistic desire, i.e., the action which promotes the common good is only the means of self-beneficence.

Similar to the psychological egoist Hobbes, Bentham (1781) also believes that conflicts may occur between self-interest and collective interest. Bentham introduces four external sanctions (religious, natural, social and legislative) to control over our own private good and promote public good which leads to universal utility. The basic principle of his ethics is to produce maximum goods, and maximum goods can be produced only when we can harmonize the psychological claim of our private good with the public good.

Later, Mill (1863) introduces the internal sanction of conscience based on the humanitarian ground of individuals which seeks good for others. By the term 'utility', Mill introduces the notion of happiness that involves not only for one individual's satisfaction, but for universal happiness. Beneficence has rarely occupied such a key role in a moral theory like Utilitarianism. Mill believes in the immense potentiality of sympathy and benevolent impulses in every human being which prompts the noble desire to promote utility, i.e., universal happiness. However, this potential human impulse for doing the noble things is very sensitive like tender plant which may be easily destroyed. Humans lose this high aspiration not only due to lack of time and opportunity, but because of 'the majority of young persons... the society into which it has thrown them, are not favorable to keeping that higher capacity in exercise' (Mill, 1863: 13). This inner benevolent impulse of human nature can be fostered and protected by education just as we need to grow the tender plant with lots of care and protection.

As consequentialists, Mill and his followers hold that an action is morally right, if an action, compared to many others, brings the greatest possible balance of beneficial outcome. Conversely, if an action, compared to many others brings the least 
possible beneficial consequence, that action is not morally right, and it must be avoided. So, the basic concern is to achieve the ideal goal of greatest possible beneficial consequences for the greatest number. However, the all-inclusive ideal consequentialist demand often puts individuals into such obligations which often go beyond their capacities. The need for beneficence in Utilitarianism becomes overdemanding in two senses (Fishkin, 1982). First, Utilitarianism may require too much for an individual in maximizing the good for others even by imposing harm on innocent individual which harm is morally unacceptable. For example, people should take isolation and quarantine methods to protect themselves and others from coronavirus which will promote overall good. However, it is not morally justified to kill the virus infected victims to maximize the overall good. Second, this theory pushes individual for maximal contribution for promoting the overall good. The cost, the contribution, the sacrifice, no matter how costly it is for the individual, will not even be counted, provided it is outweighed by the benefit of others. Suppose a wealthy benevolent individual wants to help the health department by donating some money for arranging the kits and medications in this outbreak of COVID-19. Now, the heavy demand of the situation requires if the wealthy people of each province make some charity in the health care departments, the beneficial outcome overcomes the cost. Unfortunately, in his locality no one else is ready for this charity. In this situation, it will be morally unjustified if we demand more, following utilitarianism, from the willing person to balance the cost-benefit analysis. Moreover, even if the person sacrifices his every single possession his huge selfless sacrifice will not be appreciated if it will not overcome the cost of the situation. The whole problem of over-demandingness following Utilitarianism emerges due to its sole consequentialist approach to morality. Here the rightness and wrongness of every action depend solely on its maximum beneficial consequences which completely ignores the intention or motive of the agent.

On the contrary of Mill's Utilitarianism, a different normative position is held by Deontologist Kant (1975) who distinguishes between any kind of inclination and the concept of duty. He regards benevolence as a duty that is distinct from any kind of natural inclination. For him, the duty should be universal. Since emotional inclinations are uncertain and contingent, it cannot be the motive of duty. He does not regard such charity works as a duty where people help others not from their sense of duty but due to some other motives. For him, there is a possibility of self-interest or self-inclination as the motivation behind such works. He distinguishes duty from one's own selfish interest and inclinations. According to Kant, the person holds moral worth who feels no philanthropic inclination, but who nonetheless works to help others because he knows that it is his responsibility to do. The sole determinant of an activity of being moral depends on whether the action is done from purely duty's sake or not. He moves further by accepting that his duty of benevolence derives from the virtue of love (Kant, 1964). Such love is pure practical love which is derived from wisdom and distinct from any pathological emotions. He adds that emotional love may fade away or may even disappear with the unpredictability of the situations. However, the limitation of this Kantian notion lies in its rigorous view on duty-based morality. According to Kant, only those actions hold moral worth which follow consciously the universal moral law of duty. However, in daily life, we 
are often confronted with some moral dilemmas where it is not possible to act universally with the moral law of duty. For example, telling truth is a universal moral command of law. However, if telling truth can harm another's life then we find ourselves within moral dilemmas. When the moral command of telling truth confronts with another moral command of duty which prohibits one to harm the other individual, it is morally required to choose the other one than telling truth. So, in real life it is not possible to act universally according to the command of moral law. Moreover, Kantian morality excludes all emotions including the altruistic ones from the notion of benevolence. Nonetheless, benevolence-in-itself includes the concept of love, sympathy and compassion. The duty of doing good to others presupposes the agent's concern, sympathy and love toward others.

Furthermore, Smith (1976) also holds the middle position as he rejects any such extremist position of egoism and pure altruism in his theory. He regards self-interest and other-interest as the two different instances of sympathy. The only difference between the two lies in the degree of familiarity as a person is more familiar with his own sensation than the reflective sensation of others. Smith's notion promotes beneficent acts without rejecting self-interest as vice, rather he considers it as virtue.

Finally, according to Habermas (1973), human self is not a distinct disinterested entity or unencumbered by nature, but the constitution and evolution of self-identity develops essentially from an inter-subjective communication with others. Benhabib (1992) is also inspired by Habermas's moral doctrine and accepts this inter-subjective concept of self. An individual self can be understood as a related entity among others in a community through the inter-subjective communication of speech and action between individual self with others. This standpoint differs from Kantian and Rawlsian autonomy (Rawls, 1972) where individual self is viewed as both as autonomous and as unencumbered under the 'veil of ignorance.' For Habermas, the evolution of the moral judgments of justice is intimately related with the self-other relations through which one's self-identity is constituted (Habermas, 1979). However, this is a strong formalist claim of justice-oriented theory which Benhabib rejects. In contrast to Habermas, Benhabib accepts that, 'the fairness of moral norms and the integrity of moral values can only be established via process of practical argumentation which allows participants full equality and in initiating and continuing the debate and suggesting new subject matters for conversation.' (Benhabib, 1992: 73) Benhabib regards this form of moral communication as the basic insight of her communicative ethics. Through this basic insight Benhabib establishes communicative ethics as moral justification where the moral justification comes from moral argumentation. Communicative ethics is a procedural moral theory where individuals have their freedom to share their morally justified perspectives but not like the unencumbered self within an 'original position' among predefined set of issues and legislation of Rawls. Communicative ethics encourages a more modern understanding of the self which not only provides the right to challenge political, religious or social dogmas but also endorses the right to distance oneself from the social role and content which Benhabib calls 'reflexive role-distance' (Benhabib, 1992: 73). Therefore, there is no chance of imposition or domination of others' prima facie rules, duties and obligations over one's views and understanding since every human self should always be treated like a non-instrumental entity. Benhabib develops her 
communicative ethics by viewing individual self as a related entity who has the ability and willingness of reflexive role-distance-attributed with ability and willingness to adopt others' justified rational viewpoint through an inter-subjective paradigmatic communication. An individual self is regarded here as always undergoing a psychicmoral formation, and this modern understanding of individual self "make[s] it motivationally plausible as well as rationally acceptable for them to adopt the reflexivity and universalism of communicative ethics." (Benhabib, 1992: 74).

In this framework, our moral experiences enrich and diverge through various historical and cultural struggles. So, it is illegitimate and unjustified to restrict our moral domain and experience strictly by centering justice as the core of moral life and by strictly connecting this virtue with the concept of good life. However, communicative ethics does not accept strong deontology but establishes moral argumentation of norms as the central criteria for their validity. Such theory does not restrict the notion of good life by accepting inter-connectedness with justice. This theory allows moral debate regarding our different notions of good lives and make them accessible through moral reflection and transformation. Hence, it provides a modern understanding without any prejudice since the overarching notion of good life varies through time, situation and experiences. The modern understanding of communicative ethics endorses unity of reasons among various value differentiations regardless of plurality of goodness or loss of certainty through inter-subjective communication. For example, a modern life lives with the varieties of goodness. The good life can be realized by the life of a brave soldier who fights to protect his nation or a social activist who stands for anti-war peaceful movement. However, the ethics or values cannot be prejudged since the notion of good life varies through time, situation and experiences. The variety of good life cannot be judged with any general intuitive prima facie values or norms but rather the morally good decision can be realized through the modern perspective of inter-subjective communication.

Like Benhabib's theory of justice, beneficence can also be regarded as the sum of the other-regarding virtues par excellence. The goodness of these virtues binds us in a non-relative manner. Differences may occur due to our cross-cultural perspectives, but the goodness of these virtues remains universal. For example, despite the differences between Mill's Utilitarianism and Kant's deontology on the notion of beneficence, both agree that goodness of beneficence inheres in the value of promoting good for all. Another illustration can be made on the social equality which is a universal virtue. Marx and Gandhiji both aim for an equal classless society. Now Marx supports class struggle to change the social structure of the society. On the contrary, Gandhiji endorses non-violence method which appeals to the inner goodness of humanity. Despite of their different perspectives which evolve from their own situations, time, cultures and experiences, the goodness of the virtue of equality for all human beings remains same in both cases. Benhabib prescribes for interparadigmatic dialog through which we can minimize these differences. However, these external differences do not affect the universally acceptable goodness of the virtues, but it can be reflexive through communication where we will acknowledge others' points of view with proper respect and will come to a point of agreement where there is a justification of others' positions. We can illustrate this point with an example. Suppose a person is in the middle of a situation where he finds a stranger 
and his loved ones in an equally emergency situation and on that moment, he can only rescue one among them where there is no other rescuer around. This example is quite similar with the illustration of Bernard Williams (1981) where a person is stuck between his mildly injured wife and severely injured stranger, however, we can still assume that with a sympathetic gesture toward his wife the person should rescue the severely injured stranger. Here, sympathetic gesture toward his wife is as important as rescuing the stranger. However, the situation is more difficult where both of them are equally in emergency situation and due to lack of time the person can only save one. We can find two different solutions in this situation. Firstly, we all owe a responsibility and liability toward our family members and close ones; usually an individual chooses spontaneously his duty toward the one for whom he feels direct love and care. Secondly, from the impartial point of view, we cannot prioritize between these two people only because one of them is known to me. In the second position, the individual's 'self is viewed from nowhere' (Nagel, 1970) or under the 'veil of ignorance' (Rawls, 1972). According to Nagel's impartial standpoint, since humans are rational being, they have rational requirements for their actions as well as they have rational requirements for their desires. The reason behind rational actions requiring practical judgment is formulated from an impersonal standpoint, i.e., 'provides a view of the world without giving one's location in it' (Nagel, 1970: 101). And following Rawls, initially each human being should be treated equally irrespective of one's class, caste, race, gender. This original position of every human self is viewed under the 'veil of ignorance' that is without any prior knowledge of their background. Benhabib in her communicative ethics says that in this situation we can minimize the differences by moral argumentation or communication between these two opposing views since this is the proper rational and non-instrumental way to respect others' views. For her, we can minimize the differences and can come to an agreement by respecting each other's view of justification through inter-paradigmatic dialogs. Again, there is no concept of domination or imposition of one's view among others as through this we will treat others and their views instrumentally, however, human self is a non-instrumental self. If, we do not achieve any consensus through moral communication, we will maintain reflexive role-distance with our own standpoints but there is no concept of imposition or domination on others' views in communicative ethics. We should treat others' view respectfully and beneficently. These differences occur due to different situations and various cultural perspectives which are interconnected to human self where these differences hold rational justification from their own perspectives, and everyone has the freedom of justifying their own position through inter-subjective paradigmatic dialog. Finally, as these external differences can never affect the core goodness of virtues, the goodness is established as reflexive but non-relative.

Following Benhabib, we can add that, despite the external differences between different ethical theories, the common element is that none can deny the normative importance of beneficence in moral studies. According to deontology, it is our duty to promote good for others. Like utilitarianism, other teleological theories always focus upon the telos or the consequences to maximize good or well-being for others. Being different from these two principle-based theories, virtue ethics emphasizes on building the benevolent character of the moral agent. As social beings, we should 
develop such social virtues of benevolence, cooperation, friendship, justice. The common element among these three systems is the notion of promoting good for all either based on rules or by developing virtue. The external differences among these three different theories will not affect the core goodness of the virtue of beneficence. Hence, by combining these three theories, we can say that being a rational and social human, we should value the normative importance of the core virtue of beneficence.

\section{Toward A More Credible Form of Beneficence: Appeals to the Core of Humanity}

After all this discussion, my objective is to suggest and workout a more credible form of the Principle of Beneficence. Following Benhabib, I emphasize the common essential virtue of these three ethical theories and will develop a more credible form of beneficence that will overcome both the excessive demand of Utilitarianism and the limitation of Kant's Deontology which excluded emotions as part of our natural ethical responses to others. Through the discussion, in the paper so far, I found that beneficence lies within the very essence of humanity. There is a common goodness which lies in every human being. Beneficence, as a moral principle is derived from this inner humanity of every individual. In other words, human dignity and its very essence are defined by the principle of beneficence. Despite their initial differences, utilitarianism, deontology and virtue ethics recognize this fundamental humanitarian disposition of doing good for others. Mill recognizes this as the natural human benevolent disposition of mind which is like a tender plant that needs proper care and protection through realization to grow further. The principle of beneficence as I suggest, is different from its consequential utilitarian notion as suggested by Mill since it develops from the basic understanding of humanity. No ethical system can deny this common and deepest part of morality. This version of beneficence is more credible as it does not impose over-demandingness on an individual for any maximum beneficial outcome following utilitarian calculation of beneficence over cost, and it also overcomes the rigorous duty-based limitation of Kantian deontology. This version appeals to the fundamental virtue of humanity. Finally, the credibility of this form of beneficence can be supported by the underlying transcendental humanism which is the chief feature of Indian tradition.

In this regard, I find Nicolai Hartmann's view on moral ought to be very significant. Nicolai Hartmann (1932) identifies the rigorism of Kantian notion of ought evolves from its universal emphasis on the moral worth on the character of moral ought. In Kantian ethics, the meaning of the moral laws comes from its universalistic nature of moral ought. Kantian theory endorses that the moral law is the universal commandment, imperative or claim upon an individual's moral character. The rigorism of Kantian theory evolves from its universal claim of moral worth for any action, i.e., the moral action should be performed for the sake of the moral law. Following this, an action is moral if and only if it is performed in accordance with the law. However, to be moral, it is not enough to be only in accordance with the law but it also requires one's intention to be directed toward moral values as an end. Hartmann identifies Kant's rigorism since Kantian theory confines moral worth 
within the universality of moral law. Hartmann applies ought to values and redefines the idea of morality where one's will would have to be directed toward moral values as an end. Hartmann argues that his theory will not be directly and solely concerned with the universality of moral ought, but it also focuses 'the moral values [which] constitute the supreme end of moral actions' (Hartmann, 1932: 30). Unlike Kant, Hartmann endorses that the moral worth of any actions depends on the valuational qualities they produce. According to Hartmann, a morally good person can distinguish himself as how he morally ought to be from the moral valuations of his actions. To overcome the rigorism of Kant's theory, Hartmann relocates the focus of the moral worth from the universality of moral law and applies the moral worth to moral values or goods of the actions and relates it with the agent. Precisely, Hartmann combines the moral ought with an individual's value or inner character traits. He writes,

[a]n act is of course morally valuable through its end, but not in so far as the content of the end is the moral worth of the act, and not simply in so far as it has goods in its content, but in so far as its content is a definite relation of goods to person (Hartmann, 1932: 31).

The end of a particular action has its situational value, however its moral quality is actional and has its personal value since the moral quality is related with the moral character of the agent, and it evolves from the agent's continuous striving to achieve its value, but not in its final end.

In this regard, he classifies three notions of ought: "ought in general", "ought to be" and "ought to do." Moral "ought in general" is similar to the Kantian notion of a moral imperative as it comes as a command to individual. Hartmann defines "ought to be" as "a quality of moral acts in which the reality of other values is involved, this means that this valuational intention of the acts should be so constituted, or the contents so selected, that the moral qualities inhere in the acts" (Hartmann, 1932: 33). This implies that 'ought to be' will be something actual. He argues that if the intended ought is not in accordance with the requirement, 'the act will necessarily not be as it ought to be (Hartmann, 1932: 33). For example, if one helps others only out of duty but not from the intention to be benevolent or compassionate to other-beings, then the person's act will not hold its moral worth. Since, this action does not conform the requirement of what it ought to be so in general, this action is definitely not what it ought to be in actual. So, 'ought to be so in general' is actual, and it does not only mean what on one ought to strive to be so. Ought to do demands and directs one to aim for the realization of unfulfilled value in the act itself. However, Hartman identifies that limits of the ought lie in here as here 'arises a contradiction to the law that the moral worth of a deed cannot at the same time be the value aimed at as the end in view' (Hartmann, 1932: 33). Suppose a person is intended to be ideally benevolent, and so he devotes himself into charity work, however, as a finite being, he has some materialistic limitation as well as the limitation of time and special distance. So, the ideal value for which he aims for does not accord with the value of his performing deeds. Accordingly, ought to do not always attaches to the ideal moral values, but it attaches to situational values. Nevertheless, this limitation of 
ought to do is not the limitation of ought in general as " $\mathrm{t}]$ he imperative character therefore of moral commandments, which are concerned with conduct as such, is not affected by this limit" (Hartmann, 1932: 33). Hartmann prescribes that the limitation of the actual act can be overcome by the individual's rational striving for attaining the ideal value and also clarifies that moral values are not dependent upon achieving such ideal value, but it lies in the striving itself. So, the person who aims to be ideally benevolent, the moral worth of his beneficent actions does not depend on achieving the moral value, but its moral worth arises from his continuous rational endeavor-in-itself.

Following the distinctions of Hartmann's moral ought, I differentiate the principle of beneficence in two ways. Firstly, beneficence as a moral principle or ideal moral ought that is universal and grounded in the very nature of humanity. This ought in general is actual since its intention ought to be based in the humanitarian concern toward others. If any beneficent action is not intended from one's humanitarian concern toward others, then that action will not be what it ought to be so in general. Secondly, beneficence as an active principle is situation-specific for its successful application in our daily lives. The principle of beneficence as an active principle can be applied successfully in practice where there is a harmony between the humanitarian intention of doing good and the actual situation. For example, when I would see a drowning child, the universal moral imperative of beneficence would direct me to do something good by which I can save the child, but not only from duty's sake but also from the humanitarian concern toward the child. But I can only perform it in actuality if my intention of doing good is in accordance with my actual situation. Here the actual situation primarily requires my swimming ability. Without this ability, I cannot actualize the principle of beneficence in this situation.

However, the ideal moral imperative of beneficence never stops a human being from his continuous striving for doing good to others. Following this universal moral imperative of beneficence, one despite one's own swimming incapability can run to others for help to save the child by informing the local police or localities to save the child's life. However, following the high demand for ideal beneficence, some situations become more complicated where the individual is capable of swimming but there are more than one or two or ten drowning children and equally in the same emergency. Then, the ideal goal of beneficence demands to save all which is beyond one single person's capability. Thus, beneficence as an active principle has its limitation in the situation-specific context where the demand for moral worth following the ideal imperative is too high.

Conversely, since the universal moral worth of beneficence requires us to fulfill the unfulfilled ideal moral goal and directs individuals to fulfill the ideal goal, this situation-specific limitation is not applicable to the universal moral principle of beneficence. The limitation of the actualization of the ideal moral act of beneficence in this situation can be overcome through a continuous endeavor toward achieving the ideal value of beneficence. The quality of a moral act does not depend on achieving the ideal goal, but the moral worth inheres within the genuine continuous endeavor of achieving that ideal value of the action itself. In the above situation, the person can sincerely endeavor to save as many children as he can without harming himself since it will not be wise to put himself in danger in this already endangered 
situation and since simultaneously he can inform the locality and police to try to save them all.

The moral principle of beneficence comes as a universal obligation from our core of humanity. The sincere endeavor for this conscientious effort of doing good holds the goodness and genuineness of an individual's intention. This conscientious effort is intrinsically valuable. The content of the intention of this endeavor should be universal and objective regardless of its situational perspective. Here the moral worth lies within this universal content of continuous striving to achieve the ideal value. This continuous effort to reach the ideal value is unconditional and good-in-itself. I suggest that, despite the limitation and incapability of an individual to act beneficently for all in a particular situation, the continuous effort for the ideal value of beneficence for any situation determines the moral worth of any action. Morality aims to develop an individual into a morally better person, and this conscientious effort within every individual develops the moral conduct of an individual. Thus, this version of beneficence can overcome the Kantian duty-based limitation of actualization, yet maintaining the universalization of moral value, by conjoining it with agent's moral value. Kantian duty-based theory has the limitation of actualization since here morality claims that every action should be followed by the universality of duty for duty's sake only and the moral worth of Kantian theory only focuses on this universality of duty for any action. My version of beneficence, following Hartmann, relocates the focus of the moral worth from the universality of moral dutybased beneficent actions to moral values of beneficence of the actions and relates it with the agent and combines the moral ought with an individual's value or inner character traits.

In this regard, I would also like to mention the Aristotelian concept of the mean which refers every virtue of character lies between two correlative faults or vices. Consequently, virtue represents neither excess nor deficiency but the right amount. He develops his doctrine of mean with the concept of arete or virtue per excellence. According to him, 'excellence makes what has it good, and enables it to perform its function well' (Aristotle, 1925: 1106a16-25, Nicomachean Ethics, Book II). Virtue is by nature intermediate between two extremes and it is same for all, but intermediate is not in the object but relatively to us or to be chosen by us. Aristotle illustrates this point such as if ten is too extreme and two is too little, then the intermediate is six in terms of the object according to arithmetical proposition. However, if both the athletic trainer and beginner order six pounds food for each, it will be too much for the beginner and too less for trainer. So, the intermediate is not in the object, but it should be chosen by us which is relative to us. The person with practical wisdom who has the proper understanding of virtue can efficiently choose the right intermediate of virtue for one's own self. Now, following Aristotle, this version of beneficence confirms the excellence of human being is the disposition of beneficence which derives from the common goodness of every human being and enables a human to perform well for the betterment of humanity in general. Human excellence consists in something which makes it unique and exclusive to only humans. Aristotle recognizes this uniqueness of human beings consists in reason or practical wisdom which can determine the observance of the mean of virtues relative to us. This version of beneficence also requires such practical wisdom to determine the harmony 
between one's humanitarian intention of doing good and the actual situation which is relative to one's own time, place, culture, experience and ability. Practical wisdom, of this theory, is not only the reason but the proper balance of reason and emotion since the moral value of beneficence presupposes the altruistic emotional concern such as sympathy, compassion, love for other-beings. Here, the proper balance refers the intermediate between two extremes of both reason and emotion, and it is relative to individual's capability and specific situation. Moreover, this theory not only recognizes rationality as the uniqueness of human being, but it also recognizes the inner goodness of humanity as the exclusiveness of human beings. Here, by the term 'rationality' I intended to mean the human ability of reasonable and balanced thinking, judging and acting that other animals lack. Practical wisdom, as I mentioned above, follows from such reasonable and balanced thought process of rationality. Moreover, following Aristotle's concept of mean, the goodness of any action lies in performing that action well and all the goodness is directed to achieve the ultimate state of contentment or fulfillment, called eudaimonia. The ultimate goal of every human being, following Aristotle's ethics, is to achieve that supreme excellence state of serenity or permanent state of happiness and every human action, and its goodness depends on that ultimate goal of eudaimonia. In eudaimonist virtue ethics, the virtue is only justified because of the consequences it brings about. Here the virtues are the constitutive elements of achieving the ideal state of eudaimonia. Following Aristotle, my theory also focuses on the continuous endeavor toward the betterment. In my theory as I have mentioned above, I differentiate between beneficence in general which comes as an ought and beneficence in actuality which has specific limitation based on one's capability and situation. People are aiming for the betterment, however the moral worth of my theory does not depend or determined by the consequences on how much the agent comes closest to perfection through his performance. The moral worth of my theory solely focuses on one's pure motive or genuine endeavor but not on any measurement or consequences it brings about.

Moreover, unlike utilitarianism, my version of beneficence does not impose any unfair obligation on an individual to fulfill the maximum beneficial outcome. The limitation to actualize beneficence in situation-specific context can be overcome by the continuous endeavor of an individual to achieve that ideal universal value of beneficence for any situation. This continuous effort bridges the gap between the ideal moral value of beneficence with its actualization in the real world. Only those beneficent actions hold the moral worth where the volition of continuous effort underlies the effort to achieve the value of ideal beneficence. Such continuous effort to be ideally beneficent develops the moral conduct of any individual. I have argued that every human being based on their humanity holds a moral responsibility to be beneficent toward other human. Thus, the universal moral principle of beneficence derives as a primary moral ought from the most fundamental value of humanity. The rational willingness to be morally responsible for others originates from the basic humanitarian concern for other human beings. Human beings are born with this beneficent disposition. However, this disposition is vulnerable within the world where we have to survive. Human beings become self-centered due to the continuous struggle they have to undergo to survive in this competitive world. During this continuous struggle, humans gradually become self-centered and forget their basic 
essence of humanity. The primary duty of ethics is to protect and enhance this basic humanitarian disposition of beneficence. The humanitarian concern for other-beings springs deep inside from the love for humanity in general which develops the moral disposition to be beneficent for all. Thus, this disposition to be beneficent is universally intrinsic to every human being.

The usual objection against beneficence is that it may tend to lead to injustice by overlooking minority persons' rights in a society. However, this objection is attributed with the utilitarian standpoint of beneficence where the moral worth of an action depends solely on its maximum beneficial outcome. For a utilitarian, one should always emphasize on the maximum outcome of the collective social good where a minority's claim is often overlooked in order to maintain the highest beneficial outcome for the whole society. However, this objection cannot be raised against my suggested form of beneficence, since here no such moral demand is prescribed to maximize the beneficial outcome. This version of beneficence rather focuses on the inward growth of humanity and protects the natural humanitarian disposition of concern for others. Human beings are now well-aware of their rational superiority over other species; however, they are not fully aware of their natural humanitarian disposition through which they naturally connect and cooperate with other human beings. Although whenever we are confronted with some accidental emergency, our inner goodness rises with the benevolent concern in our conscious mind, and it comes as a command to us to do something beneficent. Suppose I maintain punctuality in my office. However, when I see a person fall down from a bus on the way of my office, my inner goodness rises with concern for that person, and I run for help rather maintaining my office punctuality. Again, whenever we are facing any collective crisis and there is any worldwide threat toward whole human race like the recent outbreak of coronavirus epidemic, our goodness rises the concern not only for our own selves but for the miserable conditions of the sufferers and for the dying patients all over the world. During this situation, our inner goodness of humanity commands us to take the preventative method of isolation and quarantine not only for others' good but also one's own good and for the overall good. Again, we should take the responsibility to raise awareness among people who are not concerned of the fatality of this infection. We should increase our inner goodness and the overall concern for the humanity within us to defeat this collective crisis together.

However, this goodness gradually decreases when we do not respond to the call of our inner selves. We should respond to the command which comes from our very essence of humanity, otherwise, the superiority of human beings will be at stake since human beings are superior not only due to their rationality but also due to their humanity. My version of beneficence is not demanding that one should always have to do something good for others. This version demands that one should not ever ignore the moral command of beneficence which rises from our core goodness of humanity. Constant ignoring of the command will gradually decrease our core goodness of humanity, and we will end up like a sociopath who has ultimately lost the capacity of sensing the essence of humanity and finally recklessly hurt his own fellow-beings. The goodness of humanity always recognizes and appreciates the sense of something that is good and also the reverse of it. Based on the capability of sensing the goodness and its reverse, we can differentiate the good from the bad, 
and the inner goodness of our humanity objects whenever we see any suppression of goodness of one fellow being by other fellow-beings. Our core goodness of humanity raises its voice against any kind of suppression such as that of men over women, white over black, rich over poor, master over slave, even the suppression by humans over nature. Our goodness of humanity raises the beneficent concern for the suppressed ones and unites us all to protest and to endorse laws which can abolish such suppressions and injustice. Justice and law control such suppression externally but to abolish any kind of unfair suppression and injustice, we should nurture our inner goodness and always be conscious about our essence of humanity.

Following Benhabib, I suggest that, like justice, beneficence also equally raises concern for others. Justice deals with another person's right, obligation and claim, while beneficence touches the inner human heart. Beneficence deals with one's moral concern for others which springs from the deepest core of humanity. Justice works externally since it deals with external rules and regulations. Here I would like to add the famous quotation of a great Christian Protestant thinker, Reinhold Niebuhr, who once said, "Love is the motive, justice is the instrument" (1966). The command to be just or to maintain justice is regulated by two ways; one is by the external imposition of punishment and another one comes from the internal compulsion of being a just human as well. On the other hand, beneficent disposition is beyond any such norms and regulations since it is natural, intrinsic and develops inwardly by touching another human's heart through its purest form. This intrinsic disposition of beneficence comes as a moral ought which directs how one ought to act beneficently to others.

Nevertheless, justice is essentially required to protect everyone's legitimate rights and to maintain peace and harmony within a community. Justice in its external form connects other-beings externally by its law and regulations, whereas the disposition of beneficence unites other-beings inwardly. Therefore, justice and beneficence are complementary to each other since justice works externally which binds the community, and beneficence grows inwardly which develops an individual to become a morally better individual and unites one with others. A morally better person obeys law and maintains justice from within who is morally disposed to do good for others. The continuous striving for ideal beneficence for humanity in general can never be unjust to anyone. Moreover, the concern for other-beings is a more simple and natural disposition since this beneficence disposition is always intrinsically connected within us from the very beginning. We just need to be conscious of its existence through responding its call and develop the proper balance of reason and emotion to respond it according to our own capabilities and situation, so that we can avoid between excessively beneficent and deficiently beneficent. This disposition transcends an individual's own self-ego toward others and gets into the other human's heart through its humanitarian appeal.

The natural disposition of beneficence is fundamentally universal, although it is initially directed for the close persons. The tender disposition of beneficence develops within the close circle with whom a child grows up, i.e., within one's family members, friends and loved ones where the communication is direct, and the closeness lies in the intimate level. This disposition in its ideal level commands us to be beneficent for all where deep inside every individual feels pure love for 
the humanity. This is the ideal form of morality where the humanitarian value of beneficence transcends toward its ideal moral perfection. The continuous endeavor to develop the ideal value of beneficence from close ones to all is the fundamental universal imperative of morality, and it is a matter of cultivation to make it the conscious center from which all our actions flows.

The compulsion of this beneficence arises from one's own deeply rooted humanitarian nature. Humans continuously strive to be morally beneficent from inside, and my version of beneficence believes in this inward reformation and appeals to its inner humanitarian root. I argue that the principle of beneficence is the fundamental principle of ethics. If we go deeper to analyse the source of this compulsion, we will realize how the compulsion of beneficence is related to the core of our humanity. Once we realize that the compulsion of beneficence comes to us from our very essence of humanity where our sole existence is related to one another, we will naturally develop our inner goodness of beneficence within us as the fundamental value of morality. When everyone realizes the sole root of humanity, there will be no hatred or violence among each other despite the apparent distinction of class, caste, sex and religion; rather love will be the prime motivator for every human action. This core bond of unity among diversity can be found in Indian tradition from the proper knowledge and realization of soul or atman from ancient Vedic scriptures and the sutras of Mahayana Buddhism to the modern Indian thoughts of Swami Vivekananda, Rabindranath Tagore, Gandhiji and Ambedkar who not only realize the true essence of humanity but also apply the principle of beneficence in reality by continuously working toward the social upliftment for the well-being of humanity in general. The detailed discussion is left for some other occasion.

Acknowledgements I am thankful to Prof. Asha Mukherjee of Visva Bharati University for her suggestions and Prof. William O'Meara of James Madison university for his insightful feedbacks.

Funding There is no funding sources for this work.

\section{Declarations}

Conflict of interest There is no conflict of interest for this work.

\section{References}

Aristotle. (1925). In W. D. Ross (Ed.), Nicomachean ethics. (Vol. IX). Oxford University Press.

Benhabib, S. (1992). Situating the self: Gender, community and post-modernism in contemporary ethics (pp. 73-74). Routledge.

Bentham, J. (1781). The principles of morals and legislation. Prometheus books.

Butler, J. (1869). In W. E. Gladstone (Ed.), Complete works (pp. 1692-175). Carter.

Cumberland, R. (1672). In J. Parkin (Ed.), A treatise of the law of nature. Hilliard and Brown.

Fishkin, J. S. (1982). The limits of obligation. Yale University Press.

Habermas, J. (1973). Labor and interaction: remarks on Hegel's Jena philosophy of mind. In J. Viertel (Ed.), Theory and practice (pp. 142-170). Beacon.

Habermas, J. (1979). Moral development and ego identity. In T. McCarthy (Ed.), Communication and the evolution of society (pp. 69-94). Beacon.

Hartmann, N. (1932). Ethics, vol-2 (pp. 30-33). The MacMillan Company. 
Hobbes, T. (1651). Leviathan. Clarendon Press.

Hutcheson, F. (1725). An inquiry concerning moral good and evil. British Moralists.

Kant, I. (1964). In H. J. Paton \& M. J. Greogor (Eds.), Doctrine of virtue. Harper and Row.

Kant, I. (1975). In T. K. Abbott (Ed.), Fundamental principles of the metaphysics of morals. The BobbsMerrill Company, INC.

MacIver, R. M., \& Page, C. H. (1949). Society: An introductory analysis. Holt.

Mill, J. S. (1863). Utilitarianism (p. 13). London, UK: Parker, Son, and Bourn.

Nagel, T. (1970). The possibility of altruism (p. 101). Clarendon Press.

Niebuhr, R. (1966). An interview with Reinhold Niebuhr by Patrick Granfield. Commonweal magazine. Source: https://www.commonwealmagazine.org/interview-reinhold-niebuhr. Retrieved April 30, 2020.

Rawls, J. (1972). Theory of justice. Harvard University Press.

Smith, A. (1976). In D. D. Raphael \& A. L. Macfie (Eds.), The theory of moral sentiments. Clarendon Press.

Williams, B. (1981). Persons, character and morality. Moral luck: philosophical papers 1973-1980 (pp. 1-19). Cambridge University Press. https://doi.org/10.1017/CBO9781139165860.002

Publisher's Note Springer Nature remains neutral with regard to jurisdictional claims in published maps and institutional affiliations. 